EDITORIAL

Volume 11 Issue 32019

DOI: 10.21315/eimj2019.11.3.1

ARTICLE INFO

Submitted: 01-08-2019

Accepted: 13-08-2019

Online: 31-10-2019

\section{The Future Ready Medical Curriculum - Personalised Medical Education and SPICES 2.0}

\author{
Muhamad Saiful Bahri Yusoff
}

Department of Medical Education, School of Medical Science, Universiti Sains Malaysia, Kelantan, MALAYSIA

To cite this article: Yusoff MSB. The future ready medical curriculum - personalised medical education and SPICES 2.0. Education in Medicine Journal. 2019;11(3):1-3. https://doi.org/10.21315/ eimj2019.11.3.1

To link to this article: https://doi.org/10.21315/eimj2019.11.3.1 Education, School of Medical Sciences, Universiti Sains Malaysia, 16150 Kubang Kerian, Kelantan, Malaysia | E-mail: msaiful_bahri@usm.my

Since the inception of School of Medical Sciences (SMS), Universiti Sains Malaysia (USM) 40 years ago, the medical school adopted the SPICES educational strategies for developing its medical curriculum. The SPICES model was first introduced by Harden Sowden \& Dunn in 1984 (1), however the model had been documented in 1970s or earlier (2). For those who are not aware of the original wordings of SPICES, it represents: S - studentcentred; P - problem-based; I - integrated; C - community-based; E - electives; $\mathrm{S}$ - systematic. These six features were contrasted with six "traditional" opposite features: teacher-centred; information gathering; discipline-based; hospital-based; standard programme; apprenticeship based or opportunistic. At that time, SPICES model was considered as "modern medical education" (2) and "innovative educational strategies" (3) for medical schools around the world to develop future ready medical curriculum. Recently, Olle ten Cate (2) proposed SPICES 2.0 that refers to; $S$ - simulation-based preparation for practice; $\mathrm{P}$ - portfolio-based monitoring; I - individualised workplace learning; C competency-based education; $\mathrm{E}$ - electronic media support; S - structured workplace assessment (2). However, the opposite features were not proposed for the SPICES 2.0 model.

In SMS USM setting, the SPICES model refers to student-centered, problem-based, integrated, community-based, electives, and systematic-spiral programme (3). Recently, during the pre-curriculum review workshop series, the faculty members representing the clinical and non-clinical experts were introduced to the SPICES 2.0 model adopted from Olle ten Cate's proposal (2). The SPICES 2.0 model refers to simulationbased, portfolio-based, individualised workplace learning, competence-based, electronic support (e-support), structured workplace-based assessment, and sustainability. The SPICES 2.0 model was proposed to leverage on the advantages of technology-human interaction for designing future ready medical curriculum. In line with a recent future scenario of higher education report, higher education providers should consider features related to humantechnology relations, technology-enhanced education, values-driven education and sustainable education (4) to redesign future ready curriculum. In addition, Karlikova et al. (5) echoed that personalised medicine 


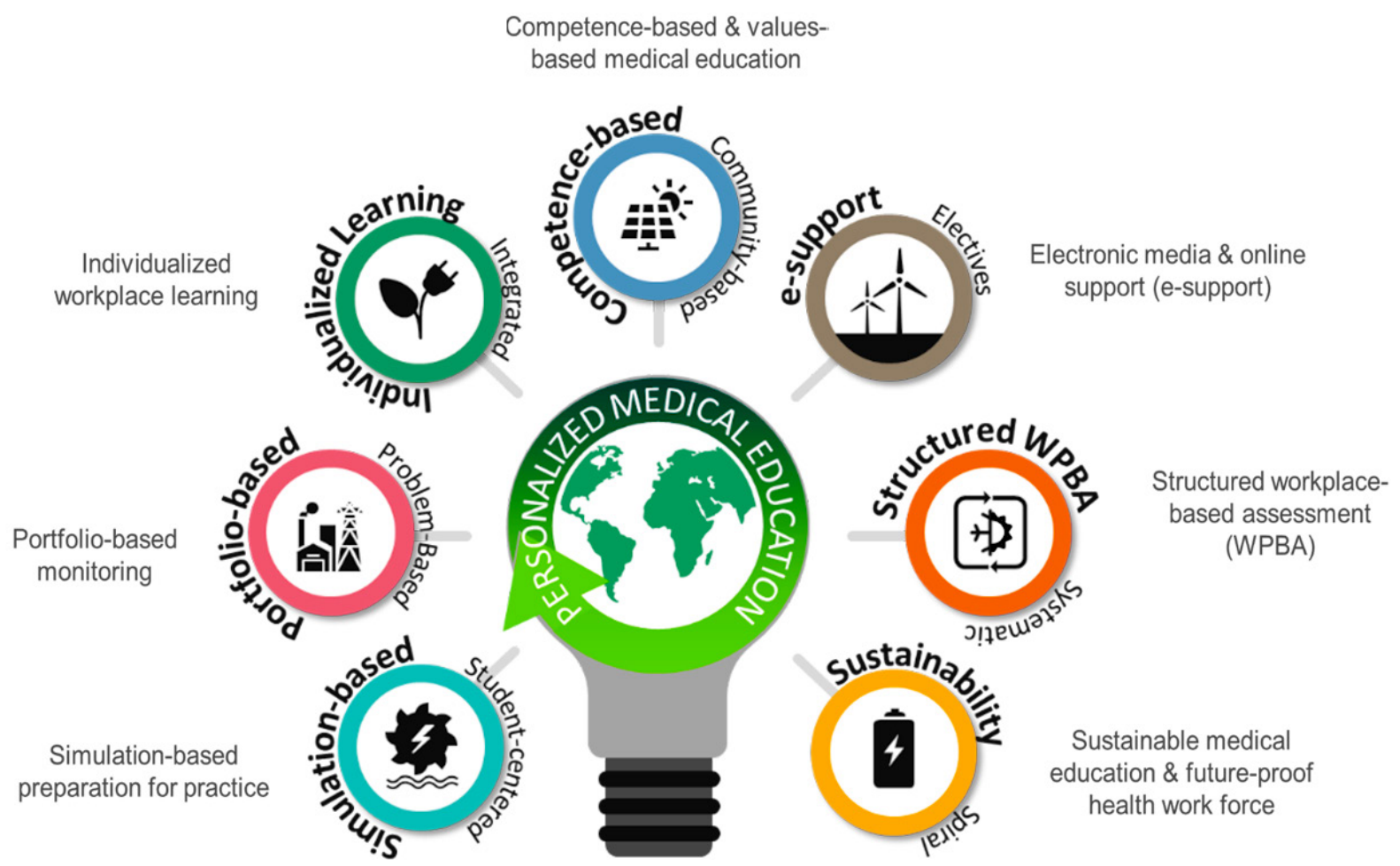

Figure 1: The SPICES 1.0 and SPICES 2.0 in SMS USM setting.

is the most likely future direction of medicine, therefore the medical education should transform its curriculum that align with the future needs of 21 st century health professionals (6). Figure 1 provides a summary of comparison between SPICES 1.0 and SPICES 2.0 as discussed by faculty members in SMS USM. From my personal observation, many modern medical schools now show most of these features (Figure 1).

My personal view is the personalised medical education should comprise the features of SPICES 1.0 and SPICES 2.0 (Figure 1), and these features should be taken into consideration for redesigning future ready medical curriculum. As being echoed by Olle ten Cate, the SPICES 1.0 has proven a fairly accurate depiction of what schools would consider modern medical education (2) and the SPICES 2.0 will augment the modernisation of medical education to cater future needs of $21 \mathrm{st}$ century health professionals (6). Nevertheless, this proposal may be questioned as still other features could fill the personalised medical education and SPICES wordings, but I believe the proposed features might serve as the food for thought that others can build on to refine the features further towards future ready medical curriculum and better medical education.

\section{REFERENCES}

1. Harden RM, Sowden S, Dunn WR. Educational strategies in curriculum development: the SPICES model. Medical Education. 1984;18(4):284-97. https://doi. org/10.1111/j.1365-2923.1984.tb01024.x

2. Cate Ot. Thirty years after SPICES - is it time for SPICES 2.0? MedEdWorld; 2014 [cited 1 August 2019]. Available from: https://www.mededworld.org/hardensblog/reflection-items/September-2014/ Thirty-years-after-SPICES-is-it-time-forSPICES-2.aspx. 
3. Zabidi-Hussin ZAMH. Curricular trends in Malaysian medical schools: innovations within. Ann Acad Med Singapore. 2006;35:647-54.

4. Yusoff MSB, Hamid AJA, Beng EOB, Azzam MGM, Sirat M. Malaysia's future higher education scenarios: fourth industrial revolution and beyond. Technical report. Putrajaya: Ministry of Education; 2018. Higher Education Policy Studies (304/ CIPPTN/650929/K145)
5. Karlikova M, Polivka Jr J, Strojil J, Topolcan O. A road toward better education in personalized medicine at universities and beyond. Personalized Medicine. 2015;12(3):259-67. https://doi.org/10.2217/ pme.14.84

6. Frenk J, Chen L, Bhutta ZA, Cohen J, Crisp N, Evans $T$, et al. Health professionals for a new century: transforming education to strengthen health systems in an interdependent world. The Lancet. 2010;376(9756):1923-58. https://doi. org/10.1016/S0140-6736(10)61854-5 